\title{
Relationship between sedentary time and central obesity in adult Korean men: Korean National Health and Nutrition Examination Survey, 2014
}

\author{
JAE-MIN PARK, YONG-JAE LEE, DUK-CHUL LEE
}

\begin{abstract}
Background. We aimed to examine the association between sedentary time and central obesity in a nationally representative sample of adult Korean men.

Methods. We included 1269 participants from the Korean National Health and Nutrition Examination Survey. Central obesity was defined as having a waist circumference (WC) $>90 \mathrm{~cm}$. The ORs and $95 \%$ Cls for central obesity were calculated using multiple logistic regression analysis.

Results. The mean values of WC tended to increase proportionally with increasing sedentary time quartiles. The prevalence of central obesity increased significantly in accordance with sedentary time quartiles. Compared to individuals in the lowest sedentary time quartile ( $\leq 4$ hours for a day), the OR for central obesity for individuals in the highest quartile ( $\geq 11$ hours for a day) was 1.81 after adjusting for confounding variables.

Conclusion. We confirmed a relationship between sedentary time and the risk prevalence of central obesity in a representative sample of adult Korean men. A public health intervention to reduce sedentary time is needed to prevent central obesity.
\end{abstract}

Natl Med J India 2021;34:15-18

\section{INTRODUCTION}

Obesity is related to multiple morbid conditions such as hypertension, ${ }^{1}$ dyslipidaemia, ${ }^{2}$ type 2 diabetes, ${ }^{3}$ cardiovascular disease, ${ }^{4}$ cerebrovascular disease,${ }^{5}$ liver disease,${ }^{6}$ neurodegenerative disease, ${ }^{7}$ osteoarthritis, ${ }^{8}$ asthma, ${ }^{9}$ depressive disorder ${ }^{10}$ and certain cancers, ${ }^{11}$ as well as increased mortality. ${ }^{12}$ As the prevalence of obesity has reached alarming levels and become an epidemic during the past few decades, public health concerns about obesity have also increased. ${ }^{13,14}$ Moreover, central obesity has been recognized as a stronger predictor of the risk of cardiovascular diseases and metabolic comorbid conditions than the body mass index (BMI). ${ }^{15-17}$

Multifactorial interactions between genetic background and

Yonsei University College of Medicine, Gangnam Severance Hospital,

211 Eonju-ro, Gangnam-gu, Seoul 06273, Republic of Korea JAE-MIN PARK, YONG-JAE LEE Department of Family Medicine

Yonsei University College of Medicine, Severance Hospital, Seoul, Korea DUK-CHUL LEE Department of Family Medicine

Correspondence to JAE-MIN PARK; milkcandy@yuhs.ac

(C) The National Medical Journal of India 2021 environmental factors such as a high calorie intake and low physical activity are considered to be the causes of central obesity. ${ }^{18}$ Because environmental factors can be controlled, the appropriate modification of environmental factors aimed at reducing central obesity may be important from a public health perspective. Sedentary behaviours are ubiquitous in developed economies, and the rapid socioeconomic growth of South Korea has resulted in substantial lifestyle changes such as westernized diets and prolonged sedentary time.

Although previous studies have reported a positive association between excessive time engaged in sedentary behaviours and an increased risk of cardiometabolic diseases, ${ }^{19,20}$ a few studies in Korea have used large-scale, randomly sampled, population-based data. Therefore, we examined the relationships between sedentary time and the risk prevalence of central obesity in a nationally representative sample of adult Korean men.

\section{METHODS}

Survey overview and study population

This cross-sectional study used data obtained from the 2014 Korean National Health and Nutrition Examination Survey (KNHANES), which was conducted by the Korea Centers for Disease Control and Prevention. The KNHANES is a nationwide, representative, population-based survey performed to evaluate the health and nutritional status of Koreans. The survey consists of a health interview survey, a nutrition survey and a health examination survey. The target population of the survey was non-institutionalized civilians in South Korea. The sampling units consisted of households that were selected through a stratified, multistage probability sampling design based on geographical location, sex distribution and age. Sampling weights that were representative of the probability of being sampled were assigned to each participant to ensure that the results represented the overall South Korean population.

A total of 7550 participants were included in the KNHANES conducted in 2014, and this survey included data from 1621 adult men aged 20-59 years. Of these 1621 adult men, we excluded those whose sedentary time and/or waist circumference (WC) data were missing $(n=330)$. Participants who had a history of cancer were also excluded from the study $(n=22)$. Therefore, 1269 participants were included in the final analysis. The KNHANES was approved by the Institutional Review Board of the Korea Centers for Disease Control and Prevention (approval number: 2013-12EXP-03-5C). In addition, this study was performed in accordance with the ethical principles of the Declaration of Helsinki. 


\section{Measurement of anthropometric and laboratory data}

At the time of the 2014 KNHANES, citizens were informed that their household had been randomly selected to voluntarily participate in a nationwide representative survey performed by the Korea Centers for Disease Control and Prevention, and that they had the right to withdraw at any time in accordance with the National Health Enhancement Act supported by the National Statistics Law of Korea. Written informed consent was obtained from all citizens who agreed to participate. Blood tests were performed for participants aged 10 years or older, and consent was obtained to use the blood samples in further studies.

Trained medical staff performed the anthropometric measurements following a standardized procedure. Height and body weight were measured to the nearest $0.1 \mathrm{~cm}$ and $0.1 \mathrm{~kg}$, respectively, while participants wore light clothing without shoes. BMI was calculated as weight $(\mathrm{kg})$ divided by the square of height $\left(\mathrm{m}^{2}\right)$. WC was measured to the nearest $0.1 \mathrm{~cm}$ at the midpoint between the lower border of the rib cage and the iliac crest at the end stage of normal expiration.

\section{Definition of each term}

In the health interview survey, there was a question that was used to assess sedentary time: 'on average how many hours per day do you sit down?' We defined sedentary time as the time spent sitting down in a day. According to the International Diabetes Federation recommendations for Asians, ${ }^{21}$ central obesity was defined as having a $\mathrm{WC} \geq 90 \mathrm{~cm}$. Exercise status was assessed via a 7-day recall method using the Korean version of the short form of the International Physical Activity Questionnaire. ${ }^{22}$ From the questionnaire, we defined a regular exerciser as an individual who participated in vigorous-intensity physical activity lasting $\geq 20$ minutes per session more than three times per week or took part in moderate-intensity physical activity lasting $\geq 30$ minutes per session more than five times per week. A current smoker was defined as one who answered affirmatively to the question in the survey that asked whether a participant was currently smoking. A regular drinker was defined as someone who drank alcoholic beverages at least twice per week. Those whose education duration was $\leq 9$ years were considered to have a 'low education' level.

\section{Statistical analysis}

Sampling weights were used to account for the complex survey design of the KNHANES; therefore, we obtained valid estimates that represented the overall South Korean population and avoided biased estimates. The sedentary time quartiles were categorized as follows: Q1 $\leq 4$ hours; Q2, 5-7 hours; Q3, 8-10 hours and $\mathrm{Q} 4, \geq 11$ hours. The characteristics of the study participants were assessed using a weighted one-way analysis of variance for continuous variables and a weighted chi-square test for categorical variables. The age-adjusted mean WC was calculated with a weighted analysis of covariance. The ORs and $95 \%$ CIs for central obesity were determined using multiple logistic regression analysis after adjusting for confounding variables (age, daily calorie intake, exercise status, smoking status, alcohol intake, residence area, education level and income). All statistical analyses were performed using SPSS statistical software version 24.0 (SPSS Inc., Chicago, IL, USA). A $\mathrm{p}$ value of $<0.05$ was considered statistically significant.

\section{RESULTS}

Table I presents the characteristics of the study participants according to the sedentary time quartiles. The mean $\mathrm{WC}$ values tended to increase proportionally with sedentary time quartiles.

Figure 1 shows the prevalence of central obesity according to the sedentary time quartiles. The prevalence of central obesity increased with increasing sedentary time quartiles as follows: $19.5 \%, 24.2 \%, 27.5 \%$ and $32.3 \%(p=0.017)$.

Table II shows the risk prevalence of central obesity according to the sedentary time quartiles. Compared with the lowest quartile, the ORs (95\% CIs) for central obesity in the highest quartiles of sedentary time were 1.81 (1.15-2.86) after adjusting for age, daily calorie intake, exercise status, smoking status, alcohol intake, residence area, education level and income.

TABLE I. Characteristics of study participants according to sedentary time quartiles (ST-Q)*

\begin{tabular}{|c|c|c|c|c|c|c|}
\hline Characteristic & All & $\begin{array}{c}\text { ST-Q1 } \\
(\leq 4 \text { hours })\end{array}$ & $\begin{array}{c}\text { ST-Q2 } \\
(5-7 \text { hours })\end{array}$ & $\begin{array}{c}\text { ST-Q3 } \\
(8-10 \text { hours })\end{array}$ & $\begin{array}{c}\text { ST-Q4 } \\
(\geq 11 \text { hours) }\end{array}$ & $\mathrm{p}$ value $\dagger$ \\
\hline Unweighted, $n$ & 1269 & 307 & 324 & 365 & 273 & \\
\hline Age (years) & $39.6(0.4)$ & $42.4(0.8)$ & $39.1(0.7)$ & $39.0(0.7)$ & $38.1 \quad(0.7)$ & 0.001 \\
\hline Body mass index $\left(\mathrm{kg} / \mathrm{m}^{2}\right)$ & $24.4(0.1)$ & $23.8(0.2)$ & $24.5(0.2)$ & $24.6(0.2)$ & $24.7(0.2)$ & 0.008 \\
\hline Waist circumference $(\mathrm{cm})$ & $84.5(0.3)$ & $83.0(0.6)$ & $84.1(0.6)$ & $85.0(0.5)$ & $85.8(0.6)$ & 0.016 \\
\hline Calorie intake (kcal/day) & 2561 & $2549(68)$ & $2521(64)$ & $2572(68)$ & $2603(76)$ & 0.871 \\
\hline Regular exercise $\ddagger(\%)$ & $19.1(1.2)$ & $23.2(2.6)$ & $24.0(2.9)$ & $15.7(2.2)$ & $13.5(2.2)$ & 0.006 \\
\hline Current smoker (\%) & $47.2(1.6)$ & $52.5(3.2)$ & $47.9(3.3)$ & $43.6(2.6)$ & $45.1(3.2)$ & 0.175 \\
\hline Regular drinker (\%) & $36.3(1.7)$ & $40.9(2.8)$ & $33.1(3.1)$ & $38.1(2.9)$ & $32.7(3.6)$ & 0.188 \\
\hline Residence in rural area $(\%)$ & $15.0(2.8)$ & $22.2(4.7)$ & $15.8(3.6)$ & $11.9(2.9)$ & $10.4(3.1)$ & 0.018 \\
\hline Low education $(\%)$ & $11.8(1.1)$ & $18.9(2.4)$ & $12.0(1.9)$ & $8.8(1.6)$ & $7.9(1.9)$ & 0.001 \\
\hline Income & & & & & & 0.085 \\
\hline 4th quartile (lowest) & $24.1(1.7)$ & $30.6(3.3)$ & $23.8(2.6)$ & $20.2(2.3)$ & $22.4(3.2)$ & - \\
\hline 3rd quartile & $26.0(1.6)$ & $26.3(2.9)$ & $29.1 \quad(2.8)$ & $25.6(2.9)$ & $22.8(3.2)$ & - \\
\hline 2nd quartile & $25.0(1.5)$ & $24.7(2.9)$ & $23.4(2.9)$ & $24.2(2.6)$ & $28.3(3.2)$ & - \\
\hline 1st quartile (highest) & $24.8(1.9)$ & $18.4(3.1)$ & $23.6(2.6)$ & $30.0(3.1)$ & $26.5(3.9)$ & - \\
\hline
\end{tabular}

*ST-Q represents sedentary time divided into quartiles for a day (ST-Q1 0-4 hours, ST-Q2 5-7 hours, ST-Q3 8-10 hours and ST-Q4 $\geq 11$ hours). Data are presented as mean (standard error) or percentage (standard error).

$\dagger \mathrm{p}$ values were obtained using weighted one-way ANOVA tests for continuous variables and weighted chi-squared tests for categorical variables.

\$Regular exercise was defined as participating in vigorous-intensity physical activity lasting $\geq 20$ minutes per session $>3$ times per week or taking part in moderate-intensity physical activity lasting $\geq 30$ minutes per session $>5$ times per week. 
TABLE II. ORs and 95\% CIs for central obesity according to sedentary time quartiles (ST-Q)

\begin{tabular}{|c|c|c|c|c|}
\hline Detail & ST-Q1 ( $\leq 4$ hours $)$ & ST-Q2 (5-7 hours) & ST-Q3 (8-10 hours) & ST-Q4 ( $\geq 11$ hours) \\
\hline Unadjusted & 1 & $1.24(0.81-1.89)$ & $1.38(0.93-2.03)$ & $1.67(1.08-2.56)$ \\
\hline Model 1 & 1 & $1.31(0.86-2.00)$ & $1.47(0.99-2.17)$ & $1.81(1.18-2.76)$ \\
\hline Model 2 & 1 & $1.41(0.88-2.25)$ & $1.59(1.01-2.48)$ & $1.76(1.11-2.80)$ \\
\hline Model 3 & 1 & $1.32(0.86-2.01)$ & $1.39(0.9-2.08)$ & $1.75(1.13-2.71)$ \\
\hline Model 4 & 1 & $1.43(0.90-2.30)$ & $1.66(1.06-2.62)$ & $1.81(1.15-2.86)$ \\
\hline
\end{tabular}

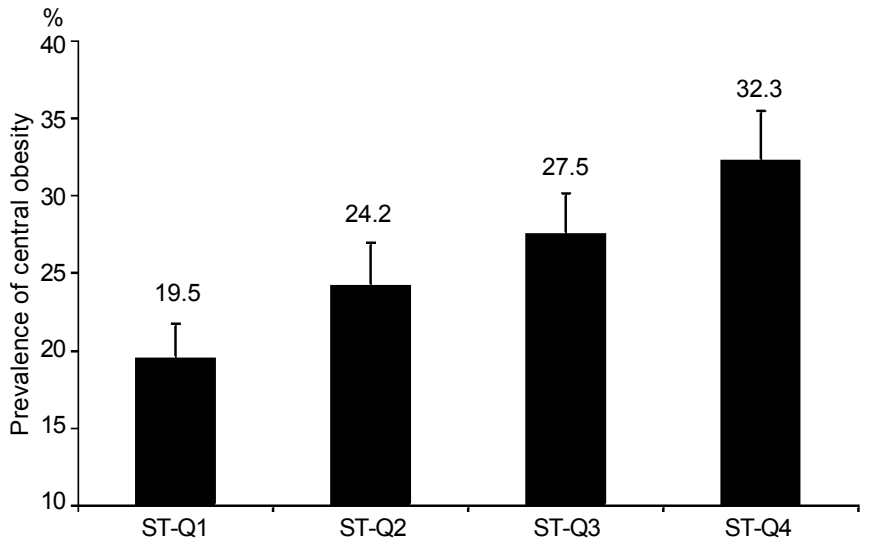

FIG 1. Prevalence of central obesity according to the sedentary time quartiles. Error bars represent standard errors

\section{DISCUSSION}

In this nationally representative cross-sectional study, we found that sedentary time was positively related to central obesity in adult Korean men. This positive association was maintained after controlling for potential confounding variables including physical activity. Our findings are in agreement with the results of previous studies showing that sedentary time is associated with increased cardiometabolic risk factors, and suggest that prolonged sedentary time is independently related to central obesity regardless of physical activity in Korean adult men. Central obesity is a key component of metabolic syndrome, and studies have shown that the prevalence of metabolic syndrome (and related central obesity) is higher in men than in women in Korea. In 2014, the prevalence of metabolic syndrome was $24.2 \%$ in men, whereas in women, it was $14.4 \% .^{23}$

Weekly physical activity of at least 150 minutes is advised for adults. ${ }^{24,25}$ The key feature of primary and secondary prevention has been known to be the intensity of such habitual physical activity, with an established preventive role in obesity, ${ }^{26}$ type 2 diabetes, ${ }^{27}$ cardiovascular disease, ${ }^{28}$ cerebrovascular disease $^{29}$ and certain cancers. ${ }^{30,31}$ According to a populationbased study, more than one-half of an average person's waking day include sedentary activities, which are universally associated with prolonged sitting, such as watching television and using the computer. ${ }^{32}$ Considering the studies suggesting that prolonged sitting has detrimental health effects in adults, this lifestyle trend is prominently risky and serious. ${ }^{33-35}$ Furthermore, it is likely that physical activity and sedentary behaviours are mutually exclusive. For example, some people who have achieved their recommended physical activity targets may seem to be highly sedentary throughout the remainder of their waking hours, whereas others who might not regularly participate in physical activity may be non-sedentary due to their involvement in leisure activities, workplace environments or both. ${ }^{36}$ Thus, for promoting public health, it is essential to stress on the importance of reducing sedentary time regardless of the level of physical activity. In addition, high levels of moderate intensity physical activity may be important. A latest meta-analysis showed that vigorous activity for 60-75 minutes/ day could mitigate the harmful effects of sitting for 8 hours or more a day. ${ }^{37}$

Lifestyle behaviours, including daily calorie and alcohol intake as well as exercise and smoking status, influence central obesity. ${ }^{38-41}$ In addition, several studies have reported that education level and household income are associated with the risk of central obesity, supporting the influence of socioeconomic status. $^{42,43}$ Our study included both lifestyle behaviours and socioeconomic status as confounding variables in the multiple regression analysis to control for potential confounding.

Our study has certain limitations that should be considered when interpreting the findings. First, we used a cross-sectional design, making it difficult to establish a causal relationship between sedentary time and central obesity in Korean men. Second, we could not fully exclude the effect of information bias because the study was based on a questionnaire survey. Selfreported sedentary time may be less accurate than objectively measured sedentary time. Third, the questions did not distinguish between sedentary leisure time, such as time spent watching television or playing video games, and productive sedentary time, such as working on the computer. Because physical activity could be differentially associated with different types of sedentary pursuits, ${ }^{44}$ the measurement of total sedentary time without distinguishing between sedentary leisure time and productive sedentary time could affect the results regarding the risk of central obesity. Despite these potential limitations, to the best of our knowledge, this is the first population-based study to show a relationship between sedentary time and central obesity in adult Korean men, which strengthens the validity of its findings.

\section{Conclusion}

We confirmed a clear and significant relationship between sedentary time and the prevalence risk of central obesity in a representative sample of adult Korean men. Public health intervention to reduce sedentary time is needed to prevent central obesity in Korea.

Conflicts of interest. None declared 


\section{REFERENCES}

1 Parrinello G, Scaglione R, Pinto A, Corrao S, Cecala M, Di Silvestre G, et al Central obesity and hypertension: The role of plasma endothelin. Am J Hypertens 1996;9:1186-91.

2 Brunzell JD, Hokanson JE. Dyslipidemia of central obesity and insulin resistance. Diabetes Care 1999;22 (Suppl 3):C10-C13.

3 Krishnan S, Rosenberg L, Djoussé L, Cupples LA, Palmer JR. Overall and central obesity and risk of type 2 diabetes in U.S. black women. Obesity (Silver Spring) 2007; 15:1860-6.

4 Goh LG, Dhaliwal SS, Welborn TA, Lee AH, Della PR. Anthropometric measurements of general and central obesity and the prediction of cardiovascular disease risk in women: A cross-sectional study. BMJ Open 2014;4:e004138.

5 Suk SH, Sacco RL, Boden-Albala B, Cheun JF, Pittman JG, Elkind MS, et al. Abdominal obesity and risk of ischemic stroke: The Northern Manhattan stroke study. Stroke 2003;34:1586-92.

6 Angulo P. Obesity and nonalcoholic fatty liver disease. Nutr Rev 2007;65: S57-S63.

7 Luchsinger JA, Cheng D, Tang MX, Schupf N, Mayeux R. Central obesity in the elderly is related to late-onset Alzheimer disease. Alzheimer Dis Assoc Disord 2012;26:101-5.

8 Batsis JA, Zbehlik AJ, Scherer EA, Barre LK, Bartels SJ. Normal weight with central obesity, physical activity, and functional decline: Data from the osteoarthritis initiative. J Am Geriatr Soc 2015;63:1552-60.

9 Chen YC, Tu YK, Huang KC, Chen PC, Chu DC, Lee YL. Pathway from central obesity to childhood asthma. Physical fitness and sedentary time are leading factors. Am J Respir Crit Care Med 2014;189:1194-203.

10 Zhao G, Ford ES, Li C, Tsai J, Dhingra S, Balluz LS. Waist circumference, abdominal obesity, and depression among overweight and obese U.S. adults: National health and nutrition examination survey 2005-2006. BMC Psychiatry 2011;11:130.

11 Lee JY, Lee HS, Lee DC, Chu SH, Jeon JY, Kim NK, et al. Visceral fat accumulation is associated with colorectal cancer in postmenopausal women. PLoS One 2014;9:e110587.

12 Jacobs EJ, Newton CC, Wang Y, Patel AV, McCullough ML, Campbell PT, et al. Waist circumference and all-cause mortality in a large US cohort. Arch Intern Med 2010;170:1293-301.

13 Flegal KM, Carroll MD, Kit BK, Ogden CL. Prevalence of obesity and trends in the distribution of body mass index among US adults, 1999-2010. JAMA 2012;307:491-7.

14 Kang HT, Shim JY, Lee HR, Park BJ, Linton JA, Lee YJ. Trends in prevalence of overweight and obesity in Korean adults, 1998-2009: The Korean national health and nutrition examination survey. J Epidemiol 2014;24:109-16.

15 Lee JW, Lee HR, Shim JY, Im JA, Kim SH, Choi H, et al. Viscerally obese women with normal body weight have greater brachial-ankle pulse wave velocity than nonviscerally obese women with excessive body weight. Clin Endocrinol (Oxf) 2007;66:572-8.

16 Lee CM, Huxley RR, Wildman RP, Woodward M. Indices of abdominal obesity are better discriminators of cardiovascular risk factors than BMI: A meta-analysis. $J$ Clin Epidemiol 2008;61:646-53.

17 Jia Z, Zhou Y, Liu X, Wang Y, Zhao X, Wang Y, et al. Comparison of different anthropometric measures as predictors of diabetes incidence in a Chinese population. Diabetes Res Clin Pract 2011;92:265-71.

18 Kopelman PG. Obesity as a medical problem. Nature 2000;404:635-43.

19 Wijndaele K, Orrow G, Ekelund U, Sharp SJ, Brage S, Griffin SJ, et al. Increasing objectively measured sedentary time increases clustered cardiometabolic risk: A 6 year analysis of the ProActive study. Diabetologia 2014;57:305-12.

20 Cooper AJ, Brage S, Ekelund U, Wareham NJ, Griffin SJ, Simmons RK. Association between objectively assessed sedentary time and physical activity with metabolic risk factors among people with recently diagnosed type 2 diabetes. Diabetologia 2014;57:73-82.

21 Alberti KG, Zimmet P, Shaw J; IDF Epidemiology Task Force Consensus Group. The metabolic syndrome-A new worldwide definition. Lancet 2005;366: 1059-62.

22 Oh JY, Yang YJ, Kim BS, Kang JH. Validity and reliability of Korean version of international physical activity questionnaire (IPAQ) short form. J Korean Acad Fam Med 2007;28:532-41.

23 Huh JH, Kang DR, Jang JY, Shin JH, Kim JY, Choi S, et al. Metabolic syndrome epidemic among Korean adults: Korean survey of cardiometabolic syndrome (2018). Atherosclerosis 2018;277:47-52.

24 World Health Organization. Global recommendations on physical activity for health. Geneva:WHO; 2010.

25 WHO Guidelines Approved by the Guidelines Review Committee. Global recommendations on physical activity for health. Geneva:WHO; 2010.

26 Sarma S, Zaric GS, Campbell MK, Gilliland J. The effect of physical activity on adult obesity: Evidence from the Canadian NPHS panel. Econ Hum Biol 2014;14:1-21.

27 Smith AD, Crippa A, Woodcock J, Brage S. Physical activity and incident type 2 diabetes mellitus: A systematic review and dose-response meta-analysis of prospective cohort studies. Diabetologia 2016;59:2527-45.

28 Lee IM, Sesso HD, Oguma Y, Paffenbarger RS Jr. Relative intensity of physical activity and risk of coronary heart disease. Circulation 2003;107:1110-16.

29 Howard VJ, McDonnell MN. Physical activity in primary stroke prevention: Just do it! Stroke 2015;46:1735-9.

30 Gonçalves AK, Dantas Florencio GL, Maisonnette de Atayde Silva MJ, Cobucci RN, Giraldo PC, Cote NM. Effects of physical activity on breast cancer prevention: A systematic review. J Phys Act Health 2014;11:445-54.

31 Mehta M, Shike M. Diet and physical activity in the prevention of colorectal cancer. J Natl Compr Canc Netw 2014;12:1721-6.

32 Matthews CE, Chen KY, Freedson PS, Buchowski MS, Beech BM, Pate RR, et al. Amount of time spent in sedentary behaviors in the United States, 2003-2004. Am $J$ Epidemiol 2008;167:875-81.

33 Dunstan DW, Salmon J, Owen N, Armstrong T, Zimmet PZ, Welborn TA, et al. Associations of TV viewing and physical activity with the metabolic syndrome in Australian adults. Diabetologia 2005;48:2254-61.

34 Hu FB, Leitzmann MF, Stampfer MJ, Colditz GA, Willett WC, Rimm EB. Physical activity and television watching in relation to risk for type 2 diabetes mellitus in men. Arch Intern Med 2001;161:1542-8.

35 Hamilton MT, Hamilton DG, Zderic TW. Role of low energy expenditure and sitting in obesity, metabolic syndrome, type 2 diabetes, and cardiovascular disease. Diabetes 2007;56:2655-67.

36 Craft LL, Zderic TW, Gapstur SM, Vaniterson EH, Thomas DM, Siddique J, et al. Evidence that women meeting physical activity guidelines do not sit less: An observational inclinometry study. Int J Behav Nutr Phys Act 2012;9:122.

37 Ekelund U, Steene-Johannessen J, Brown WJ, Fagerland MW, Owen N, Powell $\mathrm{KE}$, et al. Does physical activity attenuate, or even eliminate, the detrimental association of sitting time with mortality? A harmonised meta-analysis of data from more than 1 million men and women. Lancet 2016;388:1302-10.

38 Després JP, Lemieux I. Abdominal obesity and metabolic syndrome. Nature 2006;444:881-7.

39 Ladabaum U, Mannalithara A, Myer PA, Singh G. Obesity, abdominal obesity, physical activity, and caloric intake in US adults: 1988 to 2010 . Am J Med 2014;127:717-27.

$40 \mathrm{Kim}$ JH, Shim KW, Yoon YS, Lee SY, Kim SS, Oh SW. Cigarette smoking increases abdominal and visceral obesity but not overall fatness: An observational study. PLoS One 2012; 7:e45815.

41 Schröder H, Morales-Molina JA, Bermejo S, Barral D, Mándoli ES, Grau M, et al. Relationship of abdominal obesity with alcohol consumption at population scale. Eur J Nutr 2007;46:369-76.

42 Park SJ, Kang HT, Nam CM, Park BJ, Linton JA, Lee YJ. Sex differences in the relationship between socioeconomic status and metabolic syndrome: The Korean national health and nutrition examination survey. Diabetes Res Clin Pract 2012;96:400-6.

43 Dallongeville J, Cottel D, Ferrières J, Arveiler D, Bingham A, Ruidavets JB, et al. Household income is associated with the risk of metabolic syndrome in a sexspecific manner. Diabetes Care 2005;28:409-15.

44 Feldman DE, Barnett T, Shrier I, Rossignol M, Abenhaim L. Is physical activity differentially associated with different types of sedentary pursuits? Arch Pediatr Adolesc Med 2003;157:797-802. 